Simon J. Joseph

\title{
Jesus, Q, and the Dead Sea Scrolls
}

\section{A Judaic Approach to Q}

[Jesus, Q und die Schriftrollen vom Toten Meer. Ein judaistischer Zugang zu Q.]

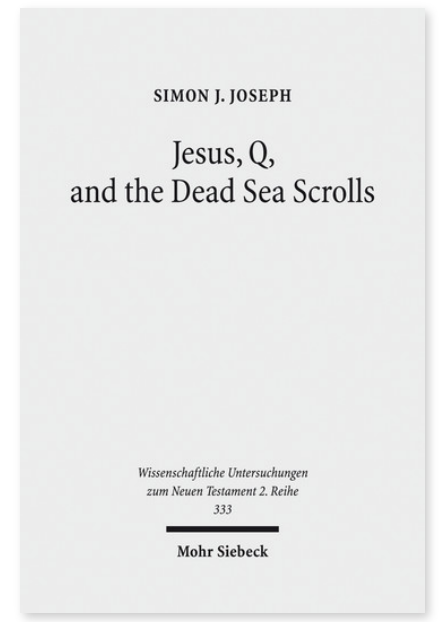

2012. XI, 267 Seiten. WUNT II 333

ISBN 978-3-16-152288-8

DOI 10.1628/978-3-16-152288-8

eBook PDF $89,00 €$

ISBN 978-3-16-152120-1

fadengeheftete Broschur $89,00 €$
Veröffentlicht auf Englisch.

Simon J. Joseph schlägt in seiner Studie ein neues Arbeitsmodell vor, um jüdische Volkszugehörigkeit, Gemeinschaft, Herkunft und kompositorische Charakteristika in Q - der ältesten und verlässlichsten Quelle für die palästinisch-jüdische JesusBewegung - zu verstehen. Mit kritischem Blick vergleicht er die wichtigsten literarischen Eigenschaften von Q 3-7, einem Abschnitt, der Johannes den Täufer einführt und der die Seligpreisungen und Jesu Antwort auf Johannes im Lichte der Schriftrollen vom Toten Meer, der Essener und der jüdischen Weisheitsbräuche und Messianismus einbezieht. Indem er eine kritische vergleichende Analyse von Q 6:20-23, Q 7:22, 4Q525 und 4Q521 durchführt, bezweifelt er mit seinem Ansatz die vorherrschende Annahme, dass Q ein galiläischer Text ist, der eine galiläische Abzweigung der frühen Jesus-Bewegung darstellt, die weder messianisch noch apokalyptisch ist.

Simon J. Joseph Born 1966; 2000 BA; 2003 MA Religious Studies, New York University; 2010 PhD, New Testament, Claremont Graduate University; currently Adjunct Professor, Dept. of Religion, California Lutheran University.
Jetzt bestellen:
https://mohrsiebeck.com/buch/jesus-q-and-the-dead-sea-scrolls-9783161522888?no_cache=1
order@mohrsiebeck.com
Telefon: +49 (0)7071-923-17
Telefax: +49 (0)7071-51104 